\title{
Comércio e lazer no início do século: $O$ caso do Derby no Recife
}

\author{
Telma de Barros Correia \\ Arquiteta pela UFPE, mestra em Desenvolvimento Regional \\ pelo MDU-UFPE e doutora em Estruturas Ambientais Urbanas \\ pela FAUUSP. Este artigo está baseado em capítulo da tese \\ de doutorado da autora, intitulada Pedra: plano e cotidiano \\ operário no sertão. O projeto urbano de Delmiro Gouveia
}

O artigo trata da criação no Recife, em fins do século 19, do Derby: Resumo um centro de comércio, serviços e lazer, que introduziu na cidade novas atitudes em face do consumo, articulando-o a formas novas de diversão e lazer. Mostra como, em termos espaciais, o Derby expressou um momento de redefinição de espaços de uso coletivo, pela incorporação de novos padrões de conforto, higiene e segurança e pela alteração da relação entre a cidade e a natureza. Mostra ainda como o malogro da experiência, após uma curta existência de menos de 1 ano, esteve relacionado a conflitos políticos entre o proprietário do Derby e os governantes pernambucanos da época.

The creation of the Derby in Recife at the end of the nineteenth century, as a commerce, services and leisure center is the focus of the following study. The Derby introduced new attitudes of consumption, articulated with new forms of diversion and leisure, into the city. The paper attempts to show, at least in spatial terms, how the Derby expressed a moment of public space redefinition through the introduction of new standards of comfort, hygene and security and through a change in the city/nature relationship. The paper also attempts to show how the failure of this experiment, after a short existance of less than one year, was related to political conflict between the owner of the Derby and the authorities in Pernambuco at that time.

Abstract 
Introdução O Derby, inaugurado em 1899 pelo comerciante de peles, Delmiro Gouveia, foi um empreendimento de grande impacto sobre o Recife. Tratou-se de um ambicioso centro de comércio, serviços e lazer que, durante uma curta existência de menos de 1 ano, alterou a rotina da cidade introduzindo formas modernas de esporte e diversão, difundindo novas atitudes em face do consumo e se constituindo em objeto, alvo e cenário de conflitos violentos entre seu proprietário e os governantes pernambucanos da época.

Em 1897, Delmiro adquiriu em leilão público as instalações do Prado da Estância. No ano seguinte, firmou contrato com a prefeitura do Recife, obtendo concessão para construção e exploração de mercado, mediante a isenção de impostos municipais pelo prazo de 25 anos, após os quais o prédio reverteria para o município sem indenização. Em 1899, construiu no local um grande mercado, uma "luxuosa hospedaria" um "vasto edifício destinado a vários jogos, café e divertimentos"e um velódromo (Galvão, 1908, p. 292-293). Em frente ao mercado implantou jardins. Também no Derby edificou sua nova residência. $\mathrm{O}$ acordo firmado com a prefeitura previa, ainda, a abertura de ruas e a construção de residências, as quais, no entanto, não chegaram a ser construídas.

A criação do Derby se inscreve em um processo mais amplo de reorganização da cidade e da vida urbana. Expressa uma alteração do ambiente da cidade, solidária a uma reorganização do consumo e do lazer, que redefine o uso do tempo livre dos indivíduos e difunde novos hábitos e símbolos de status. Testemunha uma mudança radical no cotidiano de uma parte da população, onde as lojas, restaurantes e hotéis sofisticados, as diversões e os esportes modernos vão ocupar um lugar privilegiado. Expressa, também, um momento da redefinição dos espaços de uso coletivo pela incorporação de novos padrões de higiene, conforto e segurança e pela alteração da relação da cidade com o ambiente natural. Incorpora, pela forma de introdução da energia elétrica e de máquinas modernas de diversões - como o carrossel e o magascópio - a noção da técnica como objeto de fascínio.

Imagens de progresso e civilização
Os depoimentos de observadores da época revelam a admiração causada pelo Derby junto a segmentos da população do Recife e a visitantes da cidade. O Derby surgia como expressão de progresso e civilidade, como um local ameno que ornava a cidade, 
como uma construção que incorporava os mais recentes aperfeiçoamentos relativos a conforto e higiene, como um centro de diversões modernas que trazia ao Recife os prazeres inéditos produzidos com o auxílio da técnica e da ciência:

"Luz elétrica, carrousseis, orquestrafone, barraquinhas de prendas, retrêtas, regatas, teatrinho...

Um céo no Recife sombrio e quieto de dantes.

Os bondes iam para ali todas as noites com lotações excedidas.

Era o assunto obrigatório.

- Você ainda não foi ao Derbi?

- Todo dia estou firme...Aquilo se perde!

- Logo vi!

- Agora estreou a companhia infantil.

- Só a Consuelo...heim?..."(Sette, 1981, p. 218).

“... Foi então que elle concebeu a idéa grandiosa de transformar o Recife numa cidade moderna, com hygiene, com electridade e com o conforto dos grandes centros civilisados (...) Delmiro Gouveia creou então no arrabalde do Derby o melhor centro de diversões que Pernambuco teve atá hoje. Naquelle sítio pittoresco, o seu genio progressista, introduzira os sports, creara theatro, um hotel e um mercado magnificos" (Cavalcanti, 1917, p. 7).

Quando trata de Pernambuco no livro The new Brazil, publicado em 1901, a escritora americana Marie Robinson Wright dá uma relevância especial ao Derby - que visitou em outubro de 1899-, ao qual reserva três das doze ilustrações do capítulo e um último parágrafo bastante elogioso:

"Muitos estrangeiros visitam o porto de Pernambuco todo ano, e não é raro ver meia dúzia de nacionalidades representadas nos hotéis de seus atraentes subúrbios, especialmente no Derby, que é um dos mais pitorescos lugares que se pode imaginar, com bonitas casas, sombras de arvoredos, leve movimento das águas do rio, pequenas pontes artísticas semi-enterradas na vegetação das margens, e canoas alagremente pintadas deslizando na superfície da água. Este subúrbio goza da distinção de possuir um dos melhores hotéis da América do Sul; o Hotel do Derby é perfeitamente moderno em todos os sentidos e orientado por um padrão metropolitano de serviço. O mercado do Derby é um dos maiores estabelecimentos do seu tipo, no Brasil, e está

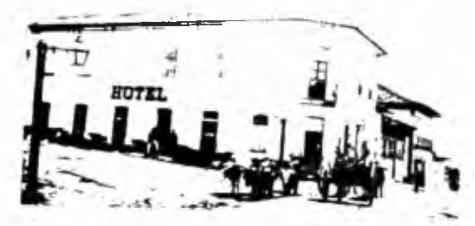




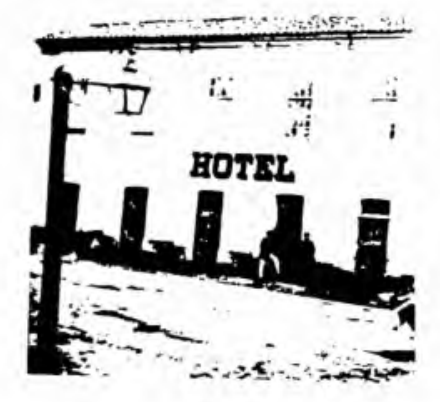

equipado para os amplos negócios que diariamente são nele realizados. O subúrbio deve seu aspecto atraente à empresa de um cidadão muito progressista, Senhor Delmiro Gouveia, o proprietário, que tem pessoalmente dirigido tudo em sintonia com o desenvolvimento do empreendimento"(Wright, 1901, p. 314).

Em janeiro de 1900, uma semana depois do incêndio do mercado do Derby, Félix Cavalcanti escrevia em seu diário:

"O que era o mercado do Derby? Um monumento. Uma obra tal que me dizem que um allemão indo visitá-lo disse que o Brasil não estava em condições de possuir uma obra daquelle porte" (Apud., Freyre, 1959, p.122).

Na ocasião, o jornal $A$ Província retratava o Mercado do Derby como um "amplo e artístico edificio" (A Província, 4 jan. 1900, p. 1). Barbosa Vianna enfatiza, na sua descrição de 1899 , a "... elegância das construções e conforto de seus aposentos, que veio preencher uma lacuna aqui existente neste ramo de serviços" (Viana, 1970, p.153). O Jornal Pequeno definiu esta hospedaria como ".. a melhor organizada e luxuosa existente no Brazil" (Jornal Pequeno, 26 ago. 1899, p. 2). Sebastião de Vasconcellos Galvão descreveu, na época, o mercado como:

"Um elegante edificio e, actualmente, no genero, o paiz não possue outro melhor nem igual. A sua área de extensão mede 129 metros de fachada por 28 de largura. É composto por dous corpos principaes com pavilhões nas extremidades, possuindo todo o edificio 18 portões e 112 janellas de venezianas. No centro do mercado ainda ergue-se outro pavilhão superior em que funciona a direcção e do qual se observa todo o movimento. As cobertas lateraes dos dous corpos principaes do edificio são suspensas por 4 linhas e 16 colunnas de ferro, e a coberta central, elevada e suspensa sobre tesouras, é circundada por ventiladores que renovam o ar e dão luz á parte interna. O mercado, dividido em muitas secções destinadas aos diversos fins da sua natureza, contém 264 compartimentos com balcões de pedra marmore, dispostos em forma de tres ruas parallelas. Chafarizes e torneiras d'agua, profusamente distribuidos por todo o edifício, com um perfeito systema de esgoto, entretêm alli o maior assieo possivel." (Galvão, 1908, p. 292.) 
..... Em livro publicado em 1900, Barbosa Vianna refere-se ao mercado como:

“... elegante edifício encerrando os mais modernos aperfeiçoamentos (...). Compõem-se de dois corpos principais, com pavilhões nas extremidades, que servem de entradas principais para o mercado, tendo no centro um pavilhão superior onde funciona a administração, e de onde se observa todo o movimento interior do mercado" (Vianna, 1908, p. 39).

Nas descrições acima, evidenciam-se, nas instalações do mercado, as preocupações relativas à higiene (iluminação, renovação do ar, asseio, sistema de abastecimento e esgotamento), ao ordenamento (repartição interna em seções, conforme a natureza do produto comercializado) e à segurança (esquema panóptico de controle a partir do local destinado à direção). Construído em alvenaria de tijolo, o mercado tinha colunas de ferro e parte da cobertura de vidro. Internamente, o prédio abrigava duas alas, divididas em seções para comércio dos produtos de natureza distintas. É provável que a concepção do Derby se tenha inspirado de algum modo no centro de comércio e lazer - The Arcade construído em Pullman em 1880, perto de Chicago e que foi incluído no roteiro turístico dos visitantes da Exposição Universal de 1893, entre os quais estava Delmiro Gouveia. De The Arcade - uma ampla construção eclética que concentrava lojas, teatro, escritórios, etc. e que tem sido apontada como precursora dos shopping centers atuais - o Derby recupera a idéia de junção entre compras, serviços e lazer.

O Derby inaugura no Recife uma nova concepção de centro de comércio, diferente do Mercado Público de São José, e mais distante ainda dos mercados existentes na primeira metade do século 19. A ênfase na higiene e na ordem, o acesso seletivo e o isolamento espacial afastam o Derby dos últimos; sua sofisticação, localização em área suburbana e a amplitude das estratégias empregadas de estímulo ao consumo o diferenciam do São José.

Os primeiros mercados existentes no Recife foram construídos em 1789 pela Câmara, para serem arrendados aos locatários. Consistiam em um mercado público composto de 62 "cazinhas" interligadas por arcadas dispostas em torno de uma "praça

\section{O mercado}

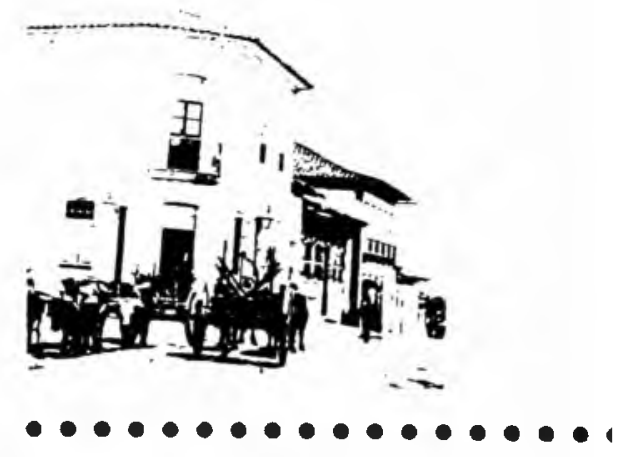


quadrada" e uma ribeira de peixe acomodando 128 bancas (Smith, 1979 , p. 350). Em parecer da Câmara do Recife a ribeira é mostrada como um "nobre edificio", voltado ao "comodo e utilidade" do povo que com "suavidade e escolha terão para o seu refectorio o peixe" (Smith, 1979, p. 357). Cerca de meio século depois, os referidos mercados tornaram-se alvo de críticas de higienistas. Em 1845, o médico Joaquim D'Aquino Fonseca criticava as condições de higiene destes mercados, relacionando-as à concentração de pobres neles. Referindo-se ao acúmulo de pedintes nas pontes da cidade - que julgava "offensivo á moral publica" e "fator de descredito aos olhos dos estrangeiros, que disso terão tristes conseqüências sobre o nosso estado de civilização" (Fonseca, 1845, p. 57), escreve:

"Não é somente naquelles lugares, que se reunem os pobres: o seu concurso é ainda maior, e mais escandaloso nas arcadas dos dois mercados publicos, onde, além da vida devassa que tem, causão tedio, e revoltão o animo daqueles que veem as nuvens de moscas, que de continuo vão do peixe ou carne ás chagas, e destas á carne ou peixe \& C." (Fonseca, 1845, p. 58).

A construção de novos mercados públicos colocava-se como estratégia voltada para estabelecer um controle central sobre o pequeno comércio de alimentos do ponto de vista sanitário e moral, criando para ele locais específicos e facilmente controláveis pela polícia municipal, dos quais seriam afastados os pobres doentes, as "mulheres devassas"e as "scenas escandalosas" que povoavam os mercados de então. Em 1855, novas denúncias contra as condições destes mercados são formuladas em relatório sobre o estado sanitário de Pernambuco:

"Aproveitando-se a commissão dos receios da invasão do Cholera-morbus, ainda tratou e pedio a construcção de mercados, em que se reunissem as substancias alimenticias, afim de que podessem estar debaixo da vigilancia dos agentes municipaes, sendo inspeccionados pela mesma comissão, ou por facultativos designados pela camara municipal (...). Existem, he verdade, dous mercados denominados - ribeiras de peixe -, em que se encontram algumas substancias alimenticias; mas elles não offerecem as necessarias accomodações, nem alli se reunem todos que vendem essas substancias; de modo que a policia municipal, que por si não he mui vigilante, como he publico e notorio, não pode exercer sua influencia sobre esses que as 
vendem pelas ruas desta cidade; além do que, tendo-se tolerado a estada de individuos chagados, e de mulheres devassas debaixo das arcadas dessas ribeira, muitas pessoas experimentam repugnancia de mandar a esses mercados, em que á noite se dão scenas de escandalosa immoralidade" (Diário de Pernambuco, 3 mar. 1855).

Alguns anos depois, a ribeira de peixes localizada junto ao Convento da Penha foi demolida e no seu lugar inaugurado, em 1875, o Mercado de São José. Questões de higiene nortearam seu projeto. A iluminação e ventilação do interior foram favorecidas por sistema que conjuga extensas clarabóias e amplos painéis de venezianas. A implantação de chafarizes, de piso impermeabilizado e de sistema de esgotamento procurava viabilizar a limpeza regular das instalações. A distribuição interna das atividades seguia normatização rígida, com a definição de áreas específicas para comércio de produtos conforme suas características (Silva, 1988, p.150-189). Atendendo às demandas colocadas por higienistas e aos padrões de bom gosto então difundidos, o Mercado de São José foi referido com entusiasmo pela imprensa e administradores públicos. Pouco antes da conclusão das obras, em discurso na Assembléia Legislativa, ressaltou-se a elegância e o "bello aspecto" de seus compartimentos internos (Lucena, 1875). Também em 1875, matéria no Diário de Pernambuco aponta no mercado beleza, "bom acabamento e solidez, comodidade, limpeza e asseio", qualificando-o como "elemento de civilização" como "... um monumento que dirá muito em prol dos nossos costumes"(Apud., Silva, 1988, p. 81).

Através, sobretudo da Revista Nouvelles Annales de la Construction e de tratados de arquitetura de autores franceses, novos padrões de mercados foram divulgados no Brasil, na segunda metade do século 19. Além de divulgar mercados construídos, a revista trazia projetos-padrões apresentados com grande riqueza de detalhes. São projetos extremamente comprometidos com questões sanitárias e que buscam explorar as potencialidades das estruturas de ferro para vencerem os grandes vãos. Os tratados incluíam recomendações gerais para a elaboração de projetos e exemplos das várias tipologias utilizadas em diferentes situações, com ênfase em projetos julgados modelares. Considerando serem os mercados basicamente centros de abastecimento de alimentos, freqüentados principalmente pelas "classes inferiores da sociedade", Reynaud recomendava que 
se evitasse neles todo luxo. Tratava-se, apenas, no seu entender, de prover um abrigo para vendedores e compradores. A comodidade, os requisitos de asseio, salubridade, simplicidade e economia são apontados como os requisitos que, julgava, deveriam presidir tais projetos (Reynald, 1878, p. 418-419). Também Cloquet defendia a necessidade de uma arquitetura simples para os mercados, indicando como condições principais a serem perseguidas uma ventilação fácil e permanente, um abundante fornecimento de água, acessos e saídas vastas e uma cobertura que preservasse as mercadorias de grandes variações sucessivas de temperatura (Cloquet, 1900, p. 175). Estes modernos mercados, no entanto, nem sempre foram objeto de admiração por parte de seus contemporâneos. Sublinhando o sentido das praças de mercado européias da Idade Média e do renascimento, enquanto cenários de parte importante da vida urbana e como espaços privilegiados pelas suas relações com as construções que as circundavam, Camillo Sitte, em livro publicado em 1889, deplorava que “... a alegre balbúrdia do mercado há muito tenha sido encarcerada nas gaiolas de ferro e vidro de um edifício fechado" (Sitte, 1992, p. 27).

No Mercado do Derby, 24 anos depois do São José, as mesmas preocupações relativas a asseio e comodidade recolocam-se. A idéia de segurança, de um espaço interno fechado, protegido de presenças indesejáveis, também volta a se impor, agora, porém, de forma mais radical. O Derby não apenas se fecha face ao seu entorno, como se isola da cidade, de seu centro comercial, evidenciando um momento mais avançado no processo de fechamento dos centros de compras. Partindo das antigas "ribeiras", com suas arcadas permanentemente abertas e acessíveis, este processo tem, no Recife, um primeiro momento em mercados como o da Boa Vista, construído na primeira metade do século 19, onde algumas lojas se voltam para as arcadas frontais abertas para a rua, enquanto outras se isolam em torno de um pátio interno, acessível por portões que se fecham ao término do horário de funcionamento do comércio. Como o Mercado de São José (1875), o do Derby se fecha em relação ao exterior: todos os seus compartimentos abrem-se para o interior do prédio. Mas em relação a estes mercados, o Derby dá um passo a mais no processo de isolamento: afasta-se do centro da cidade, situando-se em área suburbana e pouco habitada. Conforme pode ser observado em mapa da época, o Derby cercava-se quase que inteiramente pelo rio Capibaribe e por terras

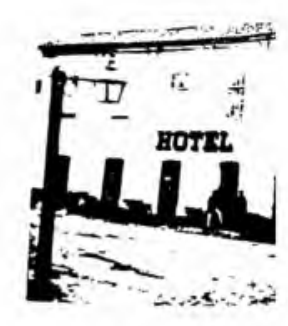


alagadas. Além do rio, que na época não se constituía mais em uma importante via de transporte, o acesso ao local dava-se por intermédio de uma única via, percorrida por linha de bondes de burro.

O fato de ser um empreendimento privado também diferenciava - Derby em relação aos mercados brasileiros da época e repercutia profundamente na sua administração. Seus proprietários alugavam os compartimentos a locatários diversos, ao mesmo tempo em que se encarregavam da promoção global do empreendimento, através de agressiva estratégia de promoção. O Derby tinha toda a sua organização voltada para incitar ao consumo. Filiava-se a um conceito das compras como uma aventura divertida e deliciosa, onde a cortesia dos vendedores, os contatos com compradores distintos, a exposição de novidades, o ambiente ameno e a circulação despreocupada eram os componentes centrais. Nele, uma nova racionalidade é estendida ao mundo das compras. Trata-se de uma forma de gestão empresarial do consumo, que é reorganizado e promovido, através de um espaço atraente - amplo, moderno, higienizado - e disciplinado. Técnicas diversas de incentivo às compras foram utilizadas. $O$ prédio, em si, era um dos instrumentos fundamentais neste sentido. A venda de artigos populares a baixo custo, atraindo clientela a um local que oferece toda sorte de bens caros e sofisticados, consistiu em outra forma adotada de incentivo ao consumo. Outro instrumento importante, neste sentido, foi a promoção de eventos e atividades de lazer - ciclismo, boliche, música -, que levavam consumidores à noite e nos fins de semana ao local. O faiscar das lâmpadas elétricas, a explosão dos fogos de artifício, a música, o movimento intenso e a sucessão de eventos esportivos atuavam no sentido de despertar no usuário a sensação de viver intensamente. Uniase ao consumo a idéia de prazer, convertendo-o em símbolo de felicidade, requinte e status.

Afastado das massas concentradas no centro da cidade, o Derby constituiu um lugar singular no cenário urbano da época. Sua organização testemunha a difusão do comércio de luxo e de estratégias inovadoras de estímulo ao consumo. Oferecer o maior número possível de mercadorias em um local confortável, protegido e atraente, constituiu-se em importante estratégia neste sentido. Tratava-se de retirar o consumidor das ruas congestionadas, 
barulhentas, tumultuadas pelo crescente tráfego de veículos e sujeitas à ação do sol e da chuva, para que ele pudesse entregar-se a esta atividade que se prometia poderia ser prazerosa e refinada: as compras. Ao mesmo tempo em que atraía consumidores potenciais ao local, afastava aqueles impossibilitados de inserir-se nesta categoria. Localizado em subúrbio, cercado de mangues, confinado em um edifício, este centro de consumo surge como um mundo à parte, no qual se procurava isolar a atividade de comprar de qualquer outra que pudesse vir a perturbá-la e resgatar os consumidores da massa difusa dos despossuídos que povoava o centro da cidade.

Uma estratégia agressiva de propaganda e de promoção do local, através da imprensa, buscava colocá-lo em evidência e firmá-lo como ponto de encontro de "famílias distintas" e local de diversões moralizadas e modernas. Outra sensível singularidade diferenciava o Mercado do Derby da tendência geral dos mercados da época: o fato de ser um empreendimento voltado, inclusive, para o comércio de produtos sofisticados. Os mercados públicos funcionavam, sobretudo, como centros de abastecimento de alimentos e objetos baratos de uso doméstico. Esta característica fazia, conforme afirmavam Reynaud e Tubeuf, referindo-se aos franceses, com que fossem freqüentados, sobretudo, pelas "classes inferiores da sociedade". Ao Derby, ao contrário, se procurava atrair sobretudo outras classes. Nele comercializava-se uma variedade ampla de mercadorias, que incluía artigos sofisticados. Lá, vendia-se gelo, todos os jornais diários, artigos para fumantes, havia filial da "Livraria Franceza", perfumarias, lojas de tecidos, de miudezas, de calçados, de quinquilharias, de louças, de brinquedos, de secos e molhados, de ferragens (Diário de Pernambuco, 04 jan. 1900; Jornal Pequeno, 24 ago. 1899 e 11 jan. 1900).

Ao isolamento espacial do empreendimento correspondia um desejo de autonomia de gestão de seus proprietários. $O$ policiamento no mercado era feito por uma guarda privada que agia sob o comando do Coronel Napoleão Duarte, sócio de Delmiro. Ante aos conflitos entre Delmiro e os governantes da época, esta guarda foi bastante ampliada, visando não apenas impor ordem e disciplina no local, como defendê-lo da ação da polícia. Reagindo contra episódio ocorrido em julho de 1899, no qual a polícia apreendeu parte do armamento utilizado por esta guarda privada, Delmiro argumenta que "... pelo regulamento do Mercado me cabe a guarda e vigilancia do mesmo, para a qual 
posso ter gente armada" (Jornal do Commércio, 21 jul. 1899, p. 4). A ênfase à segurança colocada no projeto e na administração do mercado não impediu a ocorrência de conflitos violentos:

"Às 10 horas da manhã de hoje, nos fundos do mercado do Derby dous bravi, um dos quaes tem a alcunha de Guarda Livros, atracaram-se como duas feras. Triumphou a faca de ponta, $e$ depois de algumas escaramuças, o tal Guarda Livros recebeu um ferimento horrivel no craneo. Sabendo do facto, o Coronel Napoleão dirigiu-se immediatamente ao logar do conflicto e prendeu ambos os luctadores, entregando-os depois á policia" (Jornal Pequeno, 20 out. 1899, p. 2).

Na promoção do consumo como espetáculo, distração, aventura e prazer, diferentes estratégias foram utilizadas neste empreendimento. Os proprietários empenhavam-se em colocar a diversão como finalidade do empreendimento. Ao Derby, procurava-se ligar a idéia de progresso, distinção, status e bom gosto. A noção de filantropia foi mobilizada. $O$ calendário religioso foi incorporado e suas festas reelaboradas. O prédio - com sua higiene, bom gosto, luxo, conforto, iluminação elétrica com uso cenográfico amplamente explorado e localização em área "aprazível" à margem do rio Capibaribe - surgia como uma atração em si. O "magnífico pessoal" que atendia os clientes, a música e a variedade de comidas, bebidas e jogos completavam o espetáculo proposto por este "centro de diversões":

\section{"Ao Derby!! Ao Derby!! \\ Centro de Diversões e \\ Restaurant}

Convida-se o respeitavel publico e amadores a visitar este grandioso estabelecimento, construido especialmente para tal fim, obedecendo a todas as regras de higiene e bom gosto, illuminado à luz electrica e situado na aprazivel propriedade dos exmos. srs. Gouveia \& C., Derby, onde se encontra o melhor serviço de restaurant, pastelaria e bebidas e todas as qualidades de refrescos a preços sem competencia.

Jogos de bilhar, dominó, dados, etc. e a inaugurar-se brevemente, jogos de bollas, tiro ao alvo e outros.

Os arendatários deste luxuoso estabelecimento, <<sui generis>>, desejando bem servir ao publico e às exmas. familias dispõem de magnifico pessoal para serviço e agradavel orchestra todas as noites e aos dias santificados durante dia e noite. 
Este estabelecimento conserva-se aberto de 7 horas da manhã até meia noite. Bonds para o Recife com pequenos intervallos até a hora em que se encerra o expediente do nosso estabelecimento. Uma visita, pois, ao centro de diversões.

Passar agradavel tempo!!!

Preços a competir com estabelecimentos congeneres, marcados em tabella exposta à vista dos visitantes.

\section{ABAIXO A SEMSABORIA!!! AO DERBY!!!" (A Província, 16 set. 1899, p. 2.)}

Na promoção do comércio no Derby, um outro instrumento do qual Delmiro lançou mão consistiu na aceitação, como forma de pagamento, de vales distribuídos por sociedade beneficente a pessoas pobres e por indústrias a seus operários (Jornal Pequeno, 21 ago. 1899, p. 2). Procurando tirar proveito dos constantes atrasos no pagamento dos salários dos funcionários públicos estaduais, Delmiro decidiu também repassar a estes o valor dos salários atrasados em mercadorias e dinheiro em troca de procurações autorizando-o a receber os salários:

"Gouveia \& C., para auxiliarem os funccionarios publicos na acquisição por commodos preços de comestiveis, fazendas, calçados e quaesquer outros artigos no seu mercado, deliberaram acceitar os attestados de procurações de seus honorarios em atrazo, uma vez que façam $70 \%$ de gasto no mesmo mercado, fornecendo o troco em dinheiro.

Para maior clareza demonstram o modo de transação.

O interessado apresentará no escriptorio da empreza o respectivo attestado de exercicio e passará procuração aos emprezarios para haverem do thesoureiro ou pessoa competente seu ordenado vencido, recebendo immediatamente $30 \%$ em dinheiro e o resto em ordens, conforme a nota abaixo.

Os locatários ou negociantes do mercado são obrigados a receber essas ordens como dinheiro, pois a recolherão diariamente ao escriptorio da empreza, onde serão pagas em moeda corrente.

\section{MERCADO COELHO CINTRA}

Ao sr. F... (ou ao portador d'esta) vendam os srs. locatarios ou negociantes d'este estabelecimento, generos, fazendas ou calçados ou quesquer outras mercadorias até a quantia de rs.... que pagaremos em dinheiro. 
Em... de... de 1899

Pela empreza... Contador" (Jornal Pequeno, 30 ago. 1899, p. 2).

O Derby filiava-se a uma noção de belo fundamentada em higiene, ordem e contato com a natureza. Suas construções dispunhamse de forma assimétrica, separadas por amplos jardins e espaços livres. O hotel, a residência de Delmiro e o volume central do mercado recorreram à forma dos chalés, que então se difundiam nos locais de veraneio nos subúrbios recifenses. A recuperação do ambiente natural foi mediada pela definição de novos contornos para seus elementos, numa ação que isola e retifica o rio pela construção de cais, que dispõem as flores em canteiros geometricamente traçados, que aterra os mangues.

As construções do Derby refletem uma nova relação da cidade com o rio Capibaribe. Até meados do século 19, as construções do Recife, ou se afastavam do rio, procurando, inclusive, protegerse de enchentes ou davam as costas para ele. Em face da exigüidade de espaço na área central, as construções aí localizadas chegavam até as margens do rio; nos subúrbios, no entanto, beira de rio era lugar de pobre. O desprestígio do rio no centro pode ser constatado pela implantação de algumas construções anteriores a 1850: a Igreja da Madre de Deus, o Teatro Santa Isabel e o Palácio do Governo, embora situados junto ao Capibaribe, dão as costas para ele. Tal desprestígio pode ser entendido em um momento em que o rio é o grande depósito de lixo e fezes. Uma gravura de 1848, de $\mathrm{H}$. Lewis, retrata uma destas cenas - tão deploradas pelos cronistas - de esvaziamento de um "tigre" (barril no qual se acumulavam fezes) nas margens do Capibaribe em pleno centro da cidade. Mesmo nos subúrbios elegantes de então, onde os banhos no rio se popularizavam, o Capibaribe ainda é relegado a uma posição secundária no cenário urbano, com as residências virando às costas para o rio quando situadas junto a ele ou se distanciando um pouco de suas margens. Esta relação da cidade com o rio altera-se com a construção de cais na área central e a abertura de novas ruas com casas voltadas para ele. Domesticado, definido seu curso em limites precisos e alterado seu uso, o rio habilita-se para desempenhar um novo papel, surgindo como elemento de valorização da paisagem urbana. Os prédios voltaramse para o rio na medida em que este foi isolado da cidade por obras de engenharia - aterros, construção de cais e jardins em suas margens - e teve seu uso alterado por outras destas obras -

\section{A cidade e o rio}


implantação de sistemas de coleta de lixo e de esgotamento que reduziram a sujeira do rio no centro.

Os empreendimentos do Derby têm uma relação peculiar ante este processo: construídos em momento de valorização do rio na paisagem recifense, situam-se nas margens do Capibaribe. $O$ mercado, no entanto, não estabelece qualquer relação com o rio. O hotel ao contrário, embora tenha sua entrada do lado oposto, volta-se inteiramente para o Capibaribe: para o rio abrem-se varandas e janelas dos aposentos mais privilegiados; o terraço junto ao cais converte-se em palco das grandes festas e em posto de observação das regatas promovidas pelos proprietários do estabelecimento; sua vista a partir do rio torna-se objeto de cartões postais, que valorizam o clima bucólico propiciado pelas curvas do Capibaribe e pela farta vegetação de suas margens. Nele, a natureza domesticada, alçada à condição de espetáculo, converte-se em um dos componentes essenciais de um ambiente que se quer moderno e aprazível, habilitado ao uso e deleite por indivíduos que se concebem como civilizados e requintados.

Na busca de atrativos para o Derby, a técnica constituía-se em outro dos principais elementos mobilizados. "Suas maravilhas" foram alardeadas - a magia da luz elétrica, os "quadros surprehendentes" do cinema e as engrenagens complicadas e caras dos novos aparelhos de diversão - e exibidas, com ampla publicidade no local. Referindo-se ao carrossel movido a vapor, importado dos Estados Unidos, noticia a imprensa:

"Não poude ser hontem inaugurada essa nova diversão, por não ter sido acabada a dificil montagem do custoso apparelho. Sel-oá, porém, hoje pela 6 horas da noite. Fiquem disto sciente os nossos leitores" (Jornal Pequeno, 30 out. 1899, p. 2).

O megascópio era apresentado ao público como um aparelho capaz de ampliar e dar movimentos a quadros, confrontando 0 espectador com locais e cenas as mais bonitas e surpreendentes; a técnica moderna trazendo o mundo ao Derby:

"No Derby, junto da usina de luz electrica e dentro da muralha, o Sr. S. Silva está levantando um barracão, em que, nas noites de quartas, sabados e domingos, exporá ao publico uma linda série 
de quadros historicos, mytologicos, sacros, combates navaes, personagens illustres da actualidade e antigos, factos do polo norte, tudo em ponto grande e movimentado por força do moderno apparelho da casa A. Block, de Paris, denominado Megascopio e chegado a pouco" (Jornal Pequeno, 07 out. 1899, p. 2).

Com o título "Paris no Derby", organizou-se no mercado "um pavilhão para exhibição de diversos apparelhos electricos de diversões" (Jornal Pequeno, 11 set. 1899, p. 2). A luz elétrica tinha lugar central no espetáculo oferecido pelo Derby. Referindo-se à decoração do hotel por ocasião de festa nele organizada pela colônia alemã, $A$ Província noticiava:

"Aquele pittoresco recinto, que fica á margem do Capibaribe, achava-se artisticamente embandeirado e ostentava caprichosa illuminação electrica, de esplendido effeito especialmente nas lampadas collocadas por entre a folhagem do grande e copado tamarineiro que alli existe" (A Província, 24 out. 1899, p.1).

Novas formas de esportes se constituíram em importante atrativo do Derby, através da promoção de jogos e atividades esportivas, tais como corridas de bicicleta (com casa de apostas), regatas, apresentações de ginástica, jogos de bilhar, tiro ao alvo, boliche e corridas de pedestres. Também se promoveram apresentações musicais (bandas militares, colegiais e de sociedades musicais, orquestras, concertos individuais), carrossel, queima de fogos de artifício, sorteios, exposições, exibições de filmes e peças. No Derby, festas tradicionais foram recriadas: a missa se desloca do recinto da igreja para o templo do consumo, incorpora as grandes massas, mistura-se às formas novas de diversão. As comemorações do Natal de 1899 se deram entre missa campal, salva de tiros e corridas de ciclistas:

"O DERBY

\section{A 24 E 25 DO CORRENTE MISSA CAMPAL MAGNIFICAS FESTAS PROGRAMA}

A uma hora da tarde de 24 principiarão as corridas de cyclistas, sendo o ultimo pareo de 5000 metros.

Barracas de prendas.

Grande e esplendida Arvore de Natal. 
Ao cantar do gallo 2 morteiros e 1 salva de 21 tiros annunciarão um grande fogo de artificio.

Missa campal, ás 2 horas da madrugada.

O carroussel funcionará até a ultima hora.

Todos os estabelecimentos estarão illuminados á luz electrica até o termo de todas as festas.

Musica até ao amanhecer do dia 25.

Será uma das mais bonitas e attrahentes festas de Natal havidas até hoje" (A Província, 23 dez. 1899, p. 3).

Matérias de jornal noticiavam as grandes multidões - de até 8 mil pessoas, segundo matéria no Jornal Pequeno (Jornal Pequeno, 27 dez. 1899, p. 2) - que acorriam ao Derby, elas próprias mostradas como um espetáculo à parte. A vasta campina em frente ao mercado e o amplo espaço lateral reservado às diversões eram locais privilegiados para grandes concentrações humanas, fenômeno que, até então, se restringia no Recife, sobretudo às procissões religiosas, comprimidas nas ruas estreitas do centro. No Derby, as concentrações adquirem um sentido e uma visibilidade inéditos na cidade: são massas inquietas de jovens, sobretudo, devotos da ação e da velocidade, correndo sofregamente em busca de emoções novas em meio a máquinas elétricas de diversão, luzes faiscantes, estrondos de fogos e salvas de tiros.

Com este atrativo chamado ao prazer, buscava-se estender o consumo às horas livres, comprometendo as noites e os dias santificados com a atividade. O mercado abria todos os dias das seis às vinte e duas horas. Uma promoção de eventos variados e programação diferente a cada dia direcionava-se para promover a idéia de aventura, surpresa, emoções intensas:

\section{"DERBY}

"Amanhã! - 6 do corrente - Amanhã!

Havera corridas de cyclismo e musica.

Illuminação até ás 12 horas da noite.

Bazar de prendas e outras diversões imaginadas a última hora. O carroussel sempre apontado para longa viagem.

Prepara-se grandes festas para o dia 8 do corrente, que serão annunciadas amanhã.

NO DERBY" (A Província, 02 dez. 1899, p. 3).

\section{"DERBY}

Programma das festas hoje, 8 do corrente. 
Fogos de artificio.

Corridas de cyclistas com premio de medalha grande de ouro no ultimo pareo.

A banda de musica de Afogados virá tocando em todo o seu trajecto até o Derby.

Jogos de prendas e musica no interior do mercado.

O carroussel brilhantemente se apresentará a espera de seus amadores.

Até ás 12 horas da noute acha-se illuminado todo o Derby e haverá bonds até essa mesma hora.

AO DERBY" (A Província, 08 dez. 1899, p. 3).

"AO DERBY

Fogo de artificio

Amanhã 26 do corrente

Programma

Antes da corrida dos ciclistas será annunciado o primeiro pareo por 21 salvas.

No intervallo de cada pareo, o publico se distrahirá com a asceção de morteiros e outros fogos.

Ao terminarem os pareos haverá a continuação dos fogos dirigidos pelo habil fogueteiro Augusto do Nascimento.

O carroussel sempre alegre e contente a disposição dos amadores.

O circo gymnastico funccionará, dando principio ao seu espectaculo as oito horas da noite" (Jornal Pequeno, 25 nov. 1899, p. 2).

"Derby

Novas e extraordinarias festas estão annunciadas para o domingo, no Derby, que vai ser illuminado com grande gosto artistico.

Além das corridas de velodromo onde deve realisar-se uma grande disputa de velocidade, o carroussel, que funcionará desde as 9 horas do dia, circo de cavallinhos,e banda de musica, tera $o$ publico uma divertida corrida a pé e outras sorpresas.

Para alli vão ser expelidos durante a tarde e até meia noite, bonds extraordinarios" (Jornal Pequeno, 10 nov. 1899, p. 1).

"Megascopio

Hoje e amanhã, no Derby, haverá exhibição do bello e novo apparelho francez, Megascopio.

O pavilhão armado com muita decencia, estará illuminado e embandeirado aguardando a visita do publico" (Jornal Pequeno 07 out. 1899, p. 2). 
"Derby

Hoje haverá musica no Derby, tocando a banda do 14 batalhão as seguintes peças: Guarany, Aida, La Fauvette, D. Joanita, Saffo e Rigoletto. Outras boas diversōes terão alli lugar" (Jornal Pequeno, 20 set. 1899, p. 2).

Esta interminável sucessão de eventos é coerente com uma noção que liga o descanso à ação. A reposição das energias para o trabalho não é pensada, apenas, em termos do repouso no recesso do lar, mas de sua articulação com atividades esportivas e culturais coletivas, que exercitem os músculos e estimulem os sentidos. A esta ação está indissociavelmente ligada à idéia de consumo. No Derby, promove-se a idéia de integrar a todos, independente de idade, na sociedade de consumo, atraindo ao local aqueles ainda não inseridos plenamente nela. Para tal, acenava-se com o carrossel para as crianças e com os esportes para os jovens.

\section{“DERBY!}

Novas festas para domingo, 3 do corrente.

Grande medalha de ouro para o ultimo pareo na corrida de cyclistas.

Exposição de objetos de galanteria sob sorteio.

No recinto do mercado ao lado do sul acha-se collocado um piano forte, que deslisará variadas peças para distração do publico.

Os proprietarios cogitam de uma exposição permanente.

Haverá musica e fogo de artificio.

O carroussel funcionará das 4 da tarde ás 12 horas da noute, reservando a hora gratuita já annunciada para as creancas pobres. Até a hora terminal conserva-se-ão accesos todos os fócos electricos.

AO DERBY" (A Província, 02 dez. 1899, p. 3).

Acima no esforço de promoção do Derby como local de bom tom, a filantropia - ingressos gratuitos no carrossel para crianças pobres - foi um recurso utilizado. Outras iniciativas tiveram lugar no mesmo sentido:

"Em favor dos pobres promoveram as damas de caridade um rico bazar de prendas, no Derby, devendo ter lugar a primeira exposição no dia sete próximo" (Jornal Pequeno, 04 set. 1899, p. 2).

A propaganda do Derby procurava conciliar a idéia de aventura e moralidade, pretendendo atrair tanto jovens ansiosos por novida- 
des quanto "famílias distintas" Referindo-se ao megascópio, matéria no Jornal Pequeno busca tranqüilizar "pessoas decentes" sobre o que seria exibido e sobre o ambiente onde seria feita a apresentação: "A diversão é digna da assistencia das familias, havendo assentos decentes e só tendo entrada quem trajar limpamente" (Jornal Pequeno, 28 set. 1899, p. 2). Acima, as exigências relativas ao traje surgem como meio de selecionar o público de firmar o local como ponto de encontro e diversão de "famílias distintas" - e, presumivelmente, boas consumidoras. Se ao mercado - voltado a um público consumidor maior - todos tinham acesso às formas sofisticadas de lazer e ao hotel este acesso era restrito a quem não ameaçasse a atmosfera elegante e civilizada que se procurou criar.

O Hotel do Derby foi, provavelmente, o primeiro a existir no Recife em prédio construído especialmente para esta finalidade, em um momento no qual o uso de hotéis começava a se firmar entre as elites. Em fins do século passado, conforme Gilberto Freyre, o mais freqüente era a hospedagem em residências e secundariamente em conventos (Freyre, 1959, p. 416). Pensões, mantendo muito da ordem das residências ricas e freqüentemente instaladas em casarões, foram se firmando em fins do século passado, como ponto de reunião de capitalistas e políticos e local de hospedagem. Pensões, conforme Gilberto Freyre, que eram

"... antes confortáveis que modernas; e que eram menos hotéis que sobrevivências de casas patriarcais sob a forma de pousadas elegantes." (Freyre, 1959, p. 414-415).

"Nos últimos decênios do Império, mesmo sem se destacarem por um tipo especial ou moderno de arquitetura, começaram a ser pontos de reunião nas suas salas nobres e nos seus restaurantes tanto de príncipes do comércio, da lavoura, das indústrias, das finanças como da política, das letras, do magistério (...). A nova ordem econômica encontrou nos restaurantes dos hotéis seus principais centros de rendez-vous. Centros por vezes luxuosos e até nababescos.(...) Homens que na falta de clubes discretos e elegantes onde se encontrassem, encontravam-se no meio dos grandes espelhos dos salões de hotéis..." (Freyre, 1959, p. 416-417).

Embora os conflitos entre Delmiro e os governantes pernambucanos da época possam ter afastado do Derby boa parte da elites

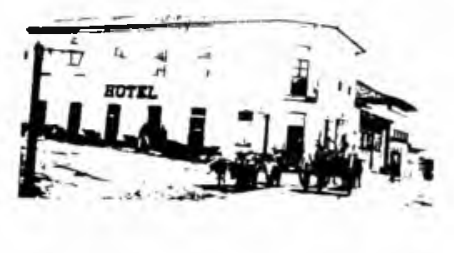

O hotel 
da cidade, o lugar conseguiu se firmar como principal local de diversões destes grupos. Em 1900, A Província mostrava o Derby como "... além de uma bella obra de arte, o mais concorrido ponto de distracção da sociedade pernambucana" (A Província, 4 jan. 1900, p.1). A menção do hotel do Derby como "um hotel para estrangeiros", feita nesse jornal, encontra confirmação em referências esparsas que a imprensa da época faz a usuários do hotel.

O incêndio Menos de um ano após o início de suas atividades, parte do mercado foi incendiada pela polícia, na seqüência de uma sucessão de atos de governantes pernambucanos voltados a inviabilizar o empreendimento. Após o incêndio, o mercado foi arrendado ao Tenente-Coronel Alberto Moreira Lopes, tendo permanecido em funcionamento por curto período a parte não atingida pelo fogo (Rocha, 1991, p. 87). Posteriormente, com a decretação da falência da empresa de Delmiro, o mercado foi entregue para o pagamento de parte das dívidas, passando a pertencer a vários bancos.

Os conflitos em torno do Derby, decorreram do alinhamento de Delmiro Gouveia com o grupo que fazia oposição a Rosa e Silva e ao Partido Republicano Federal. Na eleição de 1899, Delmiro integrou uma caravana que excursionou pelo interior do estado em propaganda eleitoral (Santos, 1947, p. 11). Esta oposição feita por Delmiro a Rosa e Silva - oligarca que comandou durante mais de 15 anos a política estadual - além de ter provocado grandes danos aos seus negócios no Recife - inviabilizou sua permanência em Pernambuco. Antigo membro do Partido Conservador no Império, Rosa e Silva, já em 1893, ingressou no Partido Republicano Federal - fundado nesse ano - e, a partir de 1896, assumiu a liderança política do estado, relegando à oposição republicanos históricos como Martins Júnior e Gonçalves Maia. Rosa e Silva dominou absoluto a política estadual de 1896 a 1911, quando indicou todos os governadores que, por sua vez, indicaram os chefes políticos locais.

Delmiro Gouveia foi um adversário ferrenho de Rosa e Silva, travando com os partidários deste, no Recife, violentas trocas de acusações pela imprensa. No primeiro semestre de 1899, uma série de conflitos envolveram Delmiro e o então prefeito do Recife, Esmeraldino Bandeira, indivíduo que se auto-intitulava a "segunda pessoa" de Rosa e Silva. Houve, da parte do prefeito, a proibição utilizando força policial - da venda de carne verde no Mercado do 
Derby. A venda do produto havia sido iniciada antes que a prefeitura se posicionasse a propósito de requerimento a ela enviado pela empresa, solicitando permissão para abater gado em um matadouro junto ao mercado, em troca do compromisso de vender a carne por um preço máximo de 900 réis o quilo, em um momento no qual os preços chegavam a 1.200 réis (Costa Porto, 1970, p. 116-118). Ante o impacto negativo, junto à opinião pública, da proibição, pelo prefeito, da venda de carne a preços reduzidos no Derby, o Jornal do Recife - alinhado à situação - publicava artigo, em maio de 1899, acusando Delmiro de especulador empenhado em ludibriar o povo, "... sob o louvável pretexto de defender os seus interesses..."(Apud., Menezes, 1991, p. 84-85). A imposição de empecilhos à drenagem, por Delmiro, de terras no Derby, foi outro momento de tensão entre ele e o prefeito do Recife. Tais conflitos se converteram em confronto aberto a partir da chamada "questão da farinha" Ante uma alta nos preços da farinha, Delmiro tomou a iniciativa de adquirir grande quantidade do produto no interior para venda no Mercado do Derby. Todo o carregamento foi apreendido por ordem do Prefeito ao chegar ao Recife. Uma vez liberada a carga, Delmiro, em ato de desagravo, organizou um desfile para o transporte da farinha do centro da cidade ao Derby (Menezes, 1991, p. 118). Atribuindo estes conflitos a um choque entre seus "... interesses commerciaes, na qualidade de proprietario do Mercado da Estancia, no Recife, e os interesses politicos do Prefeito daquella cidade...", Delmiro denunciava, em junho de 1899:

"O que se fez com o fim de prejudicar os meus interesses commerciaes não tem exemplo na historia das pequenas tramoias da politica local. Bastará dizer que se procurou até impedir que no Mercado da Estancia se vendessem generos de primeira necessidade mais barato do que no Mercado Publico..." (Jornal do Commercio, 19 jun. 1899, p. 3).

No segundo semestre desse ano, as divergências acirraram-se, após um atrito direto ocorrido no Rio de Janeiro entre Delmiro e Rosa e Silva, que resultou em agressão física contra o vicepresidente. Entre as inúmeras mensagens de apoio recebidas pelo vice-presidente da República após este episódio, consta um telegrama do governador de Pernambuco, empenhando o compromisso de um revide da parte dos "amigos" de Rosa no estado (O Paiz, 20 jul. 1899, p. 1). O tom ameaçador prossegue nos meses seguintes em matérias publicadas em jornais ligados ao governo. Simultaneamente a uma troca de acusações entre

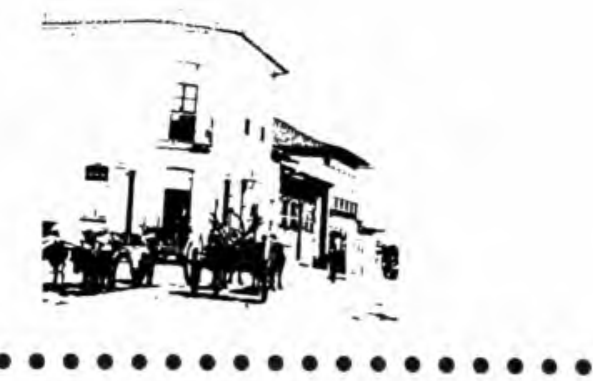


Delmiro e seus adversários, os governantes, no Recife, multiplicaram as ações contra ele e seus aliados e simpatizantes. Em julho, a polícia revistou o Mercado do Derby e a casa do sócio de Delmiro - Coronel Napoleão Duarte - apreendendo armas ( $A$ Provincia, 22 jul. 1899, p. 1). Entendendo que tanto sua vida, quanto suas propriedades estavam correndo risco, Delmiro anunciou a iminente venda do Derby a um grupo americano. Em novembro, o Jornal Pequeno lastima o fato de que o "bello melhoramento" estaria prestes a cair em mãos de estrangeiros:

"Os seus proprietarios dizem-se sem garantias precisas; e para não soffrerem perda total da enorme somma alli applicada, tiveram de entregar aos estrangeiros o mais novo e bello melhoramento de Pernambuco. Lastimando o facto, resta-nos desejar que os novos proprietarios tomem o capricho de levarem a avante os gigantescos planos dos Srs. Gouveia \& C." (Jornal Pequeno, 20 nov. 1899, p. 2).

Enquanto isso, o cerco do governo a Delmiro foi se fechando com diferentes estratégias. Na madrugada do Natal, soldados da polícia provocaram tumultos - "terror e ataques de senhora"em evento realizado no Derby, ao investirem com seus cavalos sobre uma multidão que aguardava dentro do mercado o início de uma missa campal (Apud., Menezes, 1991, p. 96). Na madrugada do dia 2 de janeiro de 1900, a polícia incendiou o Mercado do Derby e durante este dia o Recife foi tomado por frenético movimento de tropas, seguido de prisōes, entre as quais a de Delmiro, de Napoleão Duarte e de vários empregados do mercado (A Provincia, 4 jan. 1900, p. 1). Uma semana depois destes acontecimentos, retratando uma das atitudes da população da cidade ante o episódio, Félix Cavalcanti escrevia no seu diário:

"Amanheceu o dia 2 de Janeiro de 1900 no Recife, sob a mais dolorosa impressão causada pelo incendio do Derby, tendo sido lançado o fogo, ainda a horas mortas da noite de primeiro de Janeiro. Ao incendio seguiu-se a prisão do Diretor d'aquelle estabelecimento, o Coronel Delmiro Gouveia. Esta prisão foi executada com todo o apparato por um verdadeiro exercito: 50 praças de policia convenientemente municiadas ás ordens do Alferes Feitosa (...). Trancaram o preso em um quartel, deixandoo incommunicavel. Segundo a voz publica, iam matal-o envenenado. A noticia da prisão do Delmiro Gouveia espalhouse pelo Recife, creando indignação entre muita gente. $O$ 
commercio fechou em signal de protesto. Se apparecesse um daquelles homens que existiram em Pernambuco até á revolução de 48, o povo teria se levantado" (Freyre, 1959, p. 121).

Ainda em janeiro, Delmiro arrendou o Derby e viajou para a Europa. De volta a Pernambuco, percebendo que não havia clima para se manter no estado, se transferiu para Alagoas, onde construiu uma usina hidroelétrica junto à Cachoeira de Paulo Afonso e uma fábrica de linhas e um núcleo fabril em Pedra. As representações posteriores do Derby enfatizam, invariavelmente, seus aspectos inovadores, associando-o a progresso e a "prazer civilizado" Seu impacto avassalador sobre o cotidiano do Recife, associam-se à sua curta existência e final dramático, no sentido da criação de toda uma mística em torno do Derby. Mística que iria crescer com as realizações posteriores de Delmiro no Sertão.

CAVALCANTI, Plínio. Delmiro Gouveia e sua obra. Conferência realizada na Sociedade Nacional de Arquitetura por ocasião de sua reunião semanal em 30 de outubro de 1917. Rio de Janeiro; Typ. Revista dos Tribunais, 1917.

CLOQUET, L. Traité D A Architeture. Tone Quatriine. Paris. Lib. Politechnique, cei Béranger Éd., 1900.

COSTA PÔRTO. Os Tempos de Rosa e Silva. Recife: UFPE, 1970.

DIÁRIO DE PERNAMBUCO. Mercado do Derby. Revista Diária, Recife, 4 jan. 1900, p. 2.

Comissão de Hygiene Publica, relatório do estado sanitario da provincia de Pemambuco durante o anno de 1854, apresentado ao exmo. presidente da mesma provincia. Recife, 3 mar. 1855, p. 1.

JORNAL PEQUENO. Mercado do Derby. Recife, 24 ago. 1899. p. 3.

Ao Derby. Recife, 25 nov. 1899. p. 2.

Com os empregados publicos. Recife, 29 ago. 1899. p. 2.

Corroussel do Derby. Recife, 30 out. 1899. p. 2.

Damas de caridade. Recife, 4 set. 1899, p. 2.

Derby. Recife, 10 nov. 1899. p. 1

Derby. Recife, 20 set. 1899. p. 2.

Facada. Recife, 20 out. 1899. p. 2.

Hospedaria do Derby. Recife, 26 ago. 1899, p. 2.

Incêndio do Derby. Recife, 11 jan. 1900, p. 2.

Megascópio no Derby. Recife, 28 set. 1899, p. 2.

Megascópio. Recife, 7 out. 1899, p. 2.

Mercado Coelho Cintra. Recife, 21 ago. 1899, p. 2.

No Derby. Recife, 27 dez. 1899, p. 2.

Paris no Derby. Recife, 11 set. 1899, p. 2.

\section{Bibliografia}


JORNAL PEQUENO. Uma conclusão lógica. Recife, 10 jan. 1900, p. 1.

Venda do Derby. Recife, 20 nov. 1899, p. 2.

FONSECA, Dr. Joaquim D'Aquino. Collecção dos Trabalhos do Conselho Geral de Salubridade Publica da Provincia de Pernambuco, Primeiro Anno. Pernambuco: Typ. S. Caminha, 1845.

FREYRE, Gilberto. Ordem e Progresso. Obras reunidas de Gilberto Freyre. 1. série, Introdução à Historia da Sociedade Patriarcal no Brasil. Rio de Janeiro: Liv. José Olympio Editora, 1959. Ed., 1959 .

O velho Félix e suas memórias de um Cavalcanti. Rio de Janeiro: José Olympio

GALVÃO, Sebastiāo de Vasconcellos. Diccionario Chorographico, Historico e Estatistico de Pernambuco. Rio de Janeiro: Imprensa Nacional, 1908.

GOUVEIA, Delmiro. O caso Rosa e Silva. João Rosa, vulgo João Sabe Tudo. Jornal do Commercio. Rio de Janeiro, p. 4, 19 jul. 1899.

. Rosa Vice-Presidente e Rosa Sabe Tudo. Jornal do Commercio. Rio de Janeiro, p. 4, 21 jul. 1899.

LUCENA, Henrique Pereira de. Falla com que o Excellentissimo Senhor Desembarcador Henrique Pereira de Lucena Abrio A Assemblêa Legislativa Provincial de Pernambuco em primeiro de março de 1875. Pernambuco: Typ. de M. Figueroa e Filhos, 1875.

MENEZES, Hildebrando. Delmiro Gouveia: vida e morte. Recife: CEPE, 1991.

A PROVÍNCIA. Recife, 22 jul. 1899. p. 1.

. Recife, 24 out. 1899. p. 1.

Recife, 4 jan. 1900. p. 1.

. Ao Derby!! Ao Derby!!. Recife, 16 set. 1899. p. 2.

. Derby. Recife, 2 dez. 1899. p. 3.

. Derby. Recife, 8 dez. 1899. p. 3.

. O Derby. Recife, 23 dez. 1899. p. 3.

O PAIZ. Rosa e Silva. Rio de Janeiro, 20 jul. 1899. p. 1.

REYNAUD, M. Léonce. Traité D'Architecture. Deuxième Partie. Paris: Dunod Éditeur, 1878.

ROCHA, Limério Moreira da. Usina Beltrão/Fábrica Tacaruna. Um século de existência. Recife: Liber Gráfica Ed., 1991. p. 81-85.

SANTOS, Adolpho. Delmiro Gouveia. Depoimento para um estudo biográfico. Recife, s/d, 1947. (mimeo.). 44p.

SETTE, Mário. Maxambombas e Maracatus. 4 ed. Recife: Fundação de Cultura da Cidade do Recife, 1981. v. XIX: Coleção Cidade do Recife.

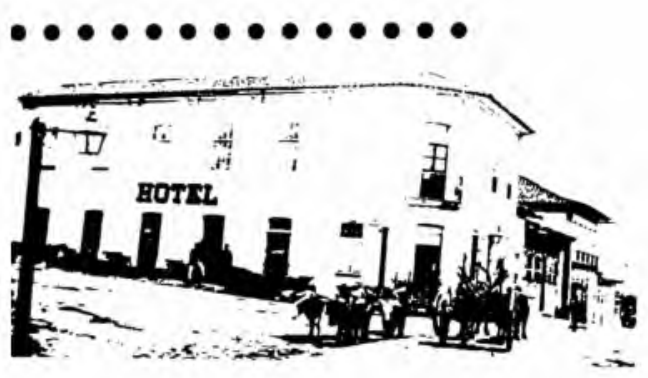

SILVA, Geraldo Gomes da. Arquitetura de ferro no Brasil. 2 ed. São Paulo, Nobel, 1988.

SITTE, Camillo. A construção das cidades segundo seus princípios artísticos. São Paulo: Ática, 1992.

SMITH, Robert C. O mercado de peixe da Vila do Recife. In: Igrejas, casas e móveis. Aspectos da arquitetura colonial brasileira. Recife: MEC/UFPE/IPHAN, 1979. p. 349-372.

TUBEUF, Georges. Traité D'Architecture. Septième Partie. Paris: Fanchon et Artus, Éd., s/data

VIANNA, C. A. J. Barbosa. Recife, capital do estado de Pernambuco. Recife: Governo de Pernambuco, Sec. de Educaçāo e Cultura, 1970 (primeira edição: 1900).

WRIGHT, Marie Robinson. The new Brazil. It's resources and attractions. historical, descriptive and industrial. Philadelphia: George Barrie \& Son, 1901. 